\title{
FELICITAS ROMANA: FELICIDADE ANTIGA, PERCEPÇÕES MODERNAS
}

\author{
Felicitas romana: \\ Ancient friendship, Modern perception \\ Renata Senna Garraffoni*
}

Certamente ainda somos conscientes de que o pensamento requer não só inteligência e profundidade, mas sobretudo coragem.

Hannah Arendt (Homens em tempos sombrios, p. 17)

\begin{abstract}
RESUMO
Considerando que Hannah Arendt propôs uma abordagem muito particular do passado greco-romano que nos encoraja a repensar a abordagem epistemológica do passado antigo, esta comunicação discute dois tópicos inter-relacionados. Em primeiro lugar, gostaria de explorar alguns aspectos da relação presente e passado antigo no pensamento de Arendt para, em seguida, considerando a Epigrafia proveniente de Pompéia, buscar formas alternativas de pensar a felicidade entre os romanos das camadas populares.
\end{abstract}

Palavras-chave: Felicidade; percepções modernas do passado antigo; Pompéia; Império Romano.

\begin{abstract}
Considering that Hannah Arendt proposed a particular kind of approach to the Greek and Roman past, which encourages us to rethink the epistemological approach to ancient past, this paper focus in two interrelated topics. First, I intend to explore some aspects of the

* Doutora em História pelo IFCH/Unicamp, professora de História Antiga do Departamento de História da UFPR (Universidade Federal do Paraná), pesquisadora associada ao NEE/Unicamp, CPA/
\end{abstract} Unicamp. 
relationship between modern present and ancient past in Hannah Arendt thought and then, considering the Epigraphic evidence from Pompeii, I would like to rethink the perceptions of happiness among the common people in ancient Rome.

Keywords: Happiness; modern perceptions of ancient past; Pompeii; Roman Empire.

\section{Hannah Arendt e o amor pelo mundo}

Falar de Hannah Arendt sempre é um grande desafio. Pensadora singular desmistificou cânones marxistas em seus textos, criticou a democracia ocidental, provocou os meios judaicos com suas análises, foi considerada empírica demais por alguns e admirada por outros. ${ }^{1}$ Portadora de um pensamento sensível ${ }^{2}$ pautado na crença das ações humanas, suas interpretações enchem de luz momentos sombrios da História. A acuidade com que discute temas complexos e experiências dolorosas contrasta com sua predisposição em acreditar no potencial criador dos homens, na possibilidade de renovação e de busca por relações que valorizem a pluralidade e as diferenças. Por todos estes motivos, Arendt se tornou uma referência no âmbito da teoria Política e cada vez mais inspira os historiadores a buscarem leituras mais dinâmicas e politizadas do passado recente ou mais antigo.

Como comecei a explorar o universo de seu pensamento há pouco tempo, gostaria de compartilhar com vocês algumas impressões iniciais que tive ao ler seus textos. O que mais me impressionou quando li, pela primeira vez, Homens em tempos sombrios ${ }^{3}$ foi sua constante ênfase na ação humana como meio de romper com processos automáticos apontando a necessidade de problematização das idéias, de pensamentos, das crenças, na

1 Sobre a recepção do pensamento de Hannh Arendt cf. MAGALHÃES, M. D. B. O pensamento e ação na obra de Hannah Arendt. Revista de História e Perspectivas, Uberlândia, n. 24, p. 27-38. jan./jun. 2001.

2 Sobre esta questão cf. D'ALLONES, M. Un coeur inteligent. Magazin Littéraire, Paris, p. 22-24., nov. 1995.

3 ARENDT, H. Homens em tempos sombrios. São Paulo: Cia. das Letras, 1987. 
importância do choque de convicções e do questionamento de nossas perspectivas habituais. A cada página que lia, percebia seu esforço em estimular o pensamento independente; a desconstrução de formas corriqueiras de amizade; do repensar de pontos de vistas unilaterais; das verdades solidificadas pela ciência moderna, enfim, sua preocupação em contextualizar as paixões humanas como parte constitutiva de subjetividades e a ação no espaço público como algo que pode proporcionar a alegria de criar o novo. Ao afirmar que a política é ação, uma forma de movimento, Arendt adota uma perspectiva antinormativa e explora o ambiente público por meio da experimentação. Assim, deslocando a política dos partidos e inserindoa no espaço público desenha um novo lugar para a liberdade, a partir da construção de subjetividades menos autoritárias e mais diversificadas. Esta atitude estimula não só a relação com o diferente, como também proporciona um constante repensar das maneiras pelas quais excluímos, muitas vezes em nosso cotidiano, a singularidade e a pluralidade. Em outras palavras, para Arendt nos constituímos como sujeitos a partir do contraste com o público, em meio à pluralidade e, por isso, é fundamental um exercício constante para criação de novas formas de ser no mundo e de agir contra a despolitização, entendida como a anulação das diferenças.

Pensando a partir desta perspectiva, Francisco Ortega afirma que Arendt define política como um risco a ser enfrentado, ou seja, um abandono de crenças e tradições sem saber o produto final desta ação; a única maneira de sacudir velhas percepções e criar novas formas de vida. ${ }^{4}$ É por isso, continua Ortega, que a percepção que Hannah tem de natalidade é fundamental, pois o nascimento é o pressuposto do agir, para que possamos sair de nossas esferas de segurança e nos confrontarmos com o desconhecido, o novo sem medo, mas com a vontade de viver novas experiências e recriar o amor pelo mundo.

Retomar aqui a idéia de natalidade como possibilidade de experimentação pareceu-me oportuno em um Evento que comemora o nascimento de Hannah por várias razões. De um ponto de vista mais amplo, diria que esta percepção de natalidade, da maneira como foi concebida por Arendt, evidencia como seu pensamento segue vivo entre intelectuais não só para

4 ORTEGA, F. Para uma política da amizade: Arendt, Derrida, Foucault. Rio de Janeiro: Relume Dumará, 2000. p. 32. 
criticar movimentos totalitários, mas também para celebrar a vida, a felicidade de pensar e compartilhar idéias e sentimentos, de construir novas percepções. Além disso, do ponto de vista teórico, Hannah nos proporciona elementos significativos para pensar o sentimento não como sinônimo de irracionalidade, mas pelo contrário, como constituinte de nosso agir no mundo, como forma de sociabilidade.

Agora, se considerarmos a especificidade da reflexão que proponho aqui, ou seja, das percepções da felicidade no mundo romano, acredito que a grande contribuição de Arendt está na maneira como ela trouxe o mundo antigo para seu presente. Em diversas obras a pensadora propõe uma valorização do mundo greco-romano, mas em nenhum momento pretendeu aplicar os conceitos ou categorias antigas a seu cotidiano, mas pelo contrário, interpretou este universo a partir de uma perspectiva política bem clara: baseou-se nos textos antigos para questionar uma tradição de pensamento que considerava obsoleta. De fato, esta sua atitude é notável, pois se retomarmos o momento em que escrevia, logo após a Segunda Guerra Mundial, ainda pairava nos estudos clássicos a sombra do nazismo e do fascismo.

Desde o final do século XIX até meados do XX, os estudos clássicos foram permeados de conceitos racistas e excludentes, idéias de superioridade e dominação muito comuns entre os estudiosos da época. Segundo Glaydson José da Silva, este período é marcado por interpretações tradicionais que pretendiam afirmar identidades modernas e garantir uma continuidade temporal, como se os seguidores de Mussolini fossem herdeiros de Roma e os de Hitler, das grandezas da Grécia antiga. ${ }^{5}$ Buscando uma relação imediata com o passado, formando uma linha de tempo ininterrupta, os estudiosos do mundo clássico, durante os períodos totalitários, uniram antigo e moderno, misturando-os de acordo com os interesses políticos nacionalistas e transformando Roma antiga em um espelho do fascismo. Mussolini, por exemplo, ao se constituir como figura pública fazia constantes comparações com os romanos antigos, em seus discursos aparecia tão poderoso quanto aos Césares de outrora.

5 SILVA, G. J. da. O aparato ideológico sobre o estudo da Antigüidade na França de 1940 1944, ou a construção do mudo gaulês antigo, romano e galo-romano sob Vichy por meio da cultura material e da tradição textual. Tese (Doutorado em História) - Departamento de História, Universidade de Campinas, Campinas, 2004. 
Esta visão, que predominou durante décadas, condenou os romanos a uma homogeneidade, como se os antigos dominassem territórios por julgar os nativos inferiores, ou seja, como se romanos fossem sinônimo de civilização e os povos conquistados de barbárie. Richard Hingley ${ }^{6}$, historiador inglês que tem se dedicado a estudar as relações entre passado antigo e política moderna, defende uma perspectiva na qual esta interpretação, vinculada a relações binárias - romanos/bárbaros, povos inferiores/superiores - indica uma leitura do passado carregada de percepção moderna, de valores autoritários e evidencia que a relação passado/presente mais que algo neutro e natural é, na verdade, uma construção política na qual os intelectuais sempre olham o passado a partir de seu presente e suas posturas políticas.

Hannah Arendt também estabeleceu uma relação entre presente e passado. Mas, ao invés de dissolver esta relação, tornou-a explícita, nunca duvidando que os gregos e romanos pudessem inspirar nossas ações no presente. No entanto, sua singularidade reside no fato que, ao contrário da perspectiva totalitária que mencionei, Arendt buscou nos gregos e romanos inspiração para criticar uma tradição autoritária de pensamento e política que ainda teimava em resistir. Nunca tratou os antigos como um espelho de sua realidade, mas como um outro que, analisado em sua especificidade, poderia desafiar as convicções modernas e abrir espaço para novas formas de sociabilidades.

É inspirada nesta perspectiva que gostaria de discutir alguns aspectos da cultura romana. Não pretendo com isso propor uma imitação deste universo, mas ao contrário, consciente de que nosso presente influencia a visão que construímos do passado, gostaria de propor uma reflexão sobre a felicidade entre os romanos, não para copiarmos suas formas de sociabilidades ou torná-las reflexos do mundo contemporâneo, mas para repensarmos e recriarmos as nossas.

6 Cf., por exemplo, HINGLEY, R. (Org.) Images of Rome: Perceptions of Ancient Rome in Europe and the United States in the Modern Age. Journal of Roman Archaeology Supplementary Series, $\mathrm{n}$. 44, 2001; HINGLEY, R. Imagens de Roma: uma perspectiva inglesa. Tradução de: Renata Senna Garraffoni. In: FUNARI, P. P. A. (Org.). Repensando o mundo antigo - Jean-Pierre Vernant e Richard Hingley, Textos Didáticos, Campinas, n. 47, 2002; HINGLEY, R., The "legacy" of Rome: the rise, decline and fall of the theory of Romanization. In: WEBSTER, J.; COOPER, N. (Orgs.). Roman Imperialism: post-colonial perspectives, Leicester, 1996, p. 35-48; HINGLEY, R. Roman officers and English gentlemen: the imperial origins of Roman Archaeology. Londres: Routledge, 2000. 


\section{Felicidade hoje}

A felicidade, tema de nossa reflexão, é motivo de discussão desde a Antigüidade, pois a busca do bem estar sempre esteve em debate entre os diferentes povos. Cada época, marcada por sua singularidade, constrói suas maneiras particulares de buscá-la, construí-la ou vivenciá-la. Em nosso mundo contemporâneo a busca pela felicidade tem se transformado em quase uma obsessão. Basta caminharmos por qualquer livraria que nos deparamos com dezenas ou centenas de livros que prometem caminhos para encontrá-la e, muitos deles, praticamente apresentam este sentimento como uma mercadoria ao alcance das mãos. Não que todos sejam ruins ou sem sentido, muito pelo contrário, pois diante de determinadas desilusões cotidianas como, por exemplo, dificuldades amorosas, perdas de entes queridos, falta de diálogo e compreensão do outro, propõem algumas alternativas práticas. No entanto, acredito que esta situação seja mais um sintoma de uma descrença no ser humano e nas diversas formas de relações que sua solução.

A felicidade, em sociedades consumistas como a nossa, é aprisionada na dimensão da esfera privada, deixando de lado sua dimensão pública. Francisco Riva, na introdução do livro A política e a felicidade, chama a atenção para este aspecto, propondo a urgência de se equilibrar estas duas esferas que compõem a felicidade. ${ }^{7}$ A tensão entre a felicidade do indivíduo e a coletiva só é possível em situações em que o aspecto individual abandona o coletivo. Tal situação, muito comum em nosso cotidiano, indica a necessidade de repensar o relacionamento público e privado e, conseqüentemente, o reconhecimento da cooperação. Riva afirma ainda que, para evitar o esfarelamento dos sentidos da felicidade ou o retorno à infelicidade causado por formas autoritárias de poder, é preciso politizar a busca pela felicidade. Isto implica em renunciarmos a nos fecharmos em nós mesmos e procurar sempre a pluralidade das relações, pela dimensão do possível. Seria esta perspectiva fundamental para a constante luta pela ação, tema tão caro a Hannah Arendt, pois é somente a ação que possibilita a renovação do viver comum. Assim, a felicidade seria deslocada; não mais estaria presa

7 BODEI, R.; PIZZOLATO, F. A política e a felicidade. Bauru: Edusc, 2000. 
unicamente no indivíduo, mas em sua relação com o outro constituindo, portanto, uma abertura para o diferente.

Os estudiosos, como Riva, que trabalham no âmbito dos sentimentos na política, quando inspirados por Hannah Arendt, constroem suas interpretações diferenciando o mundo moderno/contemporâneo do clássico, isto é, greco-romano antigo. Como comentei anteriormente, são os antigos gregos e romanos a principal fonte de inspiração para busca de ações alternativas, para interromper o fluxo automático de nossas vidas e abrir espaço para o novo. Os sentimentos e as paixões no espaço público, embora ainda seja um tema controverso entre os cientistas sociais, tem adquirido uma visibilidade maior com estes estudos. Neste sentido, o pensar e o sentir têm sido cada vez mais problematizados e se tornaram objetos de estudo dos historiadores, não para exemplificar anomalias, mas para indicar a importância que exercem na vida social. Se, por um lado, isto indica um maior entendimento das paixões humanas, por outro é importante salientar que a grande maioria destes estudos refere-se às praticas greco-latinas, mas baseia-se somente em percepções de uma camada da população, a elite letrada.

Como estudiosa da cultura romana, em especial do período imperial, tenho procurado estabelecer minhas incursões no mundo antigo a partir de um constante diálogo entre História e a Arqueologia. Esta estratégia tem permitido a possibilidade de pensar o mundo romano em seus múltiplos aspectos, pois enquanto os textos nos fornecem elementos para pensar as percepções da elite romana, a cultura material, em especial a pintura popular e os grafites de parede, nos permite ouvir as vozes das camadas menos favorecidas da população. É dentro deste contexto que gostaria de tecer alguns comentários sobre as percepções de felicidade no mundo romano.

\section{A escrita e felicidade no mundo romano}

No início dos anos de 1980, Michel Foucault publica um belo texto sobre o papel da escrita para o cuidado de si. ${ }^{8}$ Em $A$ escrita de si

8 FOUCAULT, M. A escrita de si. In: O que é um autor? Lisboa: Passagens, 1992. p. $129-160$. 
Foucault recorre a escritos de filósofos e literatos do mundo antigo, em especial o romano, para entender o papel do ato de escrever na consolidação do ser no mundo. A leitura que faz das cartas de Sêneca a Lucílio ou dos textos de Plutarco ressalta a importância que a escrita desempenhava para estes eruditos: ela seria uma maneira de recolher a leitura feita e refletir sobre ela, de construir racionalmente suas percepções cotidianas. Seria, portanto, uma maneira de unificar fragmentos heterogêneos, de consolidar sua visão de mundo.

Segundo Foucault, Sêneca acreditava que a escrita transmitia a filiação intelectual, assim como o rosto demonstrava a relação com os antepassados. A escrita expressaria para o leitor os caminhos intelectuais percorridos e, ao compartilhá-la, por meio de cartas, por exemplo, personificaria as idéias tornando presente o escritor a aquele que se dirige. Assim, como muitas vezes Sêneca ensina a Lucílio, a correspondência é um meio de unir as pessoas, de compartilhar não só o conhecimento, mas a felicidade de manter próximos os amigos ausentes.

A partir desta relação, Foucault chama a atenção para um aspecto particular do pensamento de Sêneca sobre a escrita. Para o filósofo romano escrever é, portanto, mostrar-se ao outro, aparecer para aquele que muitas vezes está distante. Seria uma maneira de se fazer presente na distância, de compartilhar aprendizados ou momentos do cotidiano, enfim, de se abrir para o outro.

Retomar os argumentos de Foucault aqui me pareceu oportuno para tratar uma característica particular do mundo romano: a sua relação com a escrita. Destaquei aqui o que se refere a Sêneca, pois este relaciona diretamente escrita com felicidade, ao afirmar que por meio da correspondência nos encontramos com o amigo ausente. No entanto, Foucault menciona uma série de outros romanos que refletiram sobre o papel da escrita como meio de expressar suas percepções, seus desejos e amores. Se por um lado homens letrados da elite romana se preocupavam em pensar o papel da escrita na formação do ethos romano, por outro, eles não eram os únicos a fixarem suas visões de mundo nas letras.

$\mathrm{O}$ ato de escrever é algo corriqueiro no mundo romano, aspecto que diferencia esta cultura de outras da Antigüidade. Enquanto no antigo Egito ou Mesopotâmia o ato de escrever se encontrava no campo do sagrado, no qual somente poucos escribas dominavam a arte dos símbolos da 
escrita, entre os romanos a gramática simplificada e o conhecimento difundido da escrita do latim em diversas camadas da população fizeram com que muitos deixassem suas marcas em diferentes superfícies. ${ }^{9}$

Há uma grande diversidade de inscrições no mundo romano, desde as chamadas monumentais, oficiais, com letras capitais para serem vistas de longe, até os grafites, pequenas incisões feitas nas paredes ou superfícies de cerâmicas, como as ânforas, por exemplo. Entre as inscrições há também as pintadas nas paredes que poderiam ser propagandas eleitorais ou de jogos de gladiadores, além da grande quantidade de lápides funerárias encontradas em diferentes regiões do Império romano. Escrever, neste contexto mais amplo, pode ser entendido com relação à memória, ou seja, com a maneira como estes romanos gostariam de ser lembrados em um tempo futuro. $\mathrm{O}$ ato de escrever pode ser interpretado, portanto, como uma maneira de preservar eventos únicos e grandiosos nas inscrições oficiais ou sentimentos e paixões nos grafites populares, constituindo um corpus das diversas possibilidades que os romanos tinham de celebrar a vida.

O interessante das inscrições é que elas não se restringem às percepções da camada aristocrática da população. Pelo contrário, elas constituem um instrumento versátil para conhecermos as visões de mundo de pessoas simples, escravos, libertos, livres de condição pobre, mulheres, enfim, sujeitos que constituíram parte do Império romano, mas que nem sempre foram ouvidos pela historiografia clássica. Para entramos neste universo, gostaria de centrar as próximas linhas em uma análise da cidade de Pompéia, localizada na Campânia romana, atual sul da Itália. É a partir de suas paredes que gostaria de discutir alguns aspectos da felicidade entre os romanos mais humildes.

\section{Felicidade Ontem-paredes de Pompéia e o ethos popular}

Pompéia, localizada próxima à bacia de Nápolis, é considerada pelos estudiosos um dos mais importantes sítios arqueológicos do mundo

9 Sobre esta questão, cf. GARRAFFONI, R. S; FUNARI, P. P. A. História Antiga na sala de aula. Textos Didáticos, n. 51, IFCH/UNICAMP, Campinas, 2004. 
antigo. Muitos acreditam que esta cidade surgiu como um núcleo de agricultores e pescadores oscos na Idade do ferro. Desde o século VIII a.C., Pompéia foi habitada por diferentes povos e, por ser próxima ao mar, sempre favoreceu a circulação de pessoas. Assim, oscos, etruscos, gregos, samnitas e romanos circularam por este espaço em diversos períodos tornando a cidade de um Pompéia um importante local de comércio e veraneio. ${ }^{10}$

Soterrada pelo vulcão Vesúvio no ano de 79 d.C., a particularidade deste sítio arqueológico ainda impressiona: se por um lado o Vesúvio causou pânico, desespero e morte ao explodir, por outro ajudou a preservar inúmeros aspectos cotidianos de uma pequena cidade conquistada e administrada pelos romanos a partir do século I a.C. Em suas ruas encontramos edifícios de diferentes períodos bem conservados e em suas paredes percebemos um universo de expressões latinas ou gregas das mais variadas espécies. Lendo estas paredes é impossível não se emocionar, afinal rimos com suas piadas, encaramos seus desafios e mistérios, encontramos os candidatos a cargos públicos de outrora e os espetáculos tão esperados.

Dentro deste universo de letras, gostaria de me ater às inscrições de caráter popular, com destaque para os grafites. Diferentemente das inscrições oficiais que eram pintadas para serem vistas a longa distância, os grafites eram pequenos e precisavam ser vistos de perto. Sulcados nas paredes com um estilete (em latim graphium), os grafites produziam uma relação distinta com o público: eram pessoais e o leitor tinha que se aproximar da parede para poder enxergá-los.

Em geral eram escritos em ambientes fechados, embora muitos sejam encontrados nas paredes externas das casas pompeianas. Impulsivo, imediato e espontâneo o grafite é um registro singular que marca um momento específico ou uma necessidade pessoal de deixar registrado uma insatisfação, uma piada ou uma declaração de amor tornando-se, portanto,

10 Há várias publicações sobre a história de Pompéia em português. Cf, por exemplo, FEITOSA, L. C. Amor e sexualidade: o masculino e o feminino em grafites de Pompéia. São Paulo: Annablume/Fapesp, 2005. CAVICCHIOLI, M. R. As representações da sexualidade na iconografia pompeiana. Dissertação (Mestrado) - Departamento de História, Unicamp, Campinas, 2004. 
uma fonte de inestimável valor para o estudo dos anseios e paixões cotidianas a partir de uma perspectiva coletiva. ${ }^{11}$

Para esta ocasião, selecionei alguns grafites e um painel pompeiano, que são datados do século I d.C., cujo tema central são reflexões acerca da felicidade. A escolha destes grafites não foi aleatória, procurei reunir aqui exemplos de como os romanos comuns pensavam a felicidade em seu dia a dia. Ao todo são quatro grafites e um painel encontrado ao lado de fora de um estabelecimento com um falo esculpido em baixo relevo.

Iniciemos a análise pelos grafites. Nas paredes de casas pompeianas ou nas colunas de um pórtico lemos o seguinte:

1. (Grat)ae nostrae feliciter (perp)etuo rogo domna per(Venere)m Físicate rogo ni me (...)us babeto mei memoriam.

(CIL, IV, 6865)

[A minha querida Grata, com felicidade eterna. Te peço, senhora minha, por Vênus Física, que você não se esqueça de mim. Me tenha sempre em teus pensamentos! $]^{12}$

2. Si potes et non uis cur gaudia differs spemque foues et cras usque redirei ubes? (Er)go coge mori quem sine te uinere coges. Múnus erit certe non cruciasse boni. Quod spes eripuit spes certe redd(i)t amanti.

(CIL, IV, 1837)

[Se você pode e não deseja, porque adia a felicidade e acalenta a esperança, me dizendo sempre para retornar amanhã? Assim você força a morrer alguém que obriga a viver sem ti. Será um presente ao menos não me atormentar. Certamente a esperança devolve ao amante o que a própria esperança arrebatou]

3. (H)ic sumus felices. Valiamus recte.

(CIL, IV, 8657)

[Aqui somos felizes. E continuamos firmes]

11 De acordo com Funari: "o grafismo popular diferenciava-se, desde o início, pelo seu caráter coletivo: não se trata de refletir um mundo distante, como no interior das mansões, mas de retratar, nas paredes externas, a vida concreta, as paixões populares em sua imediaticidade.” (FUNARI, P. P. A. $L a$ cultura popular en la Antigüedad Clásica. Sevilha: Graficas Sol: 1989, p. 39). Sobre a questão da imediaticidade do grafite cf., também, BARBET, A. La representation des gladiateurs dans la peinture murale romaine. Les Gladiateurs: Lattes, Toulouse, 1987, p. 69-74.

12 A tradução dos quatro primeiros grafites é de Lourdes Feitosa. Cf.: FEITOSA, L. C. Amor e sexualidade: o masculino e o feminino em grafites de Pompéia. São Paulo: Annablume/Fapesp, 2005. 
4. (H)ic (h)abitamus: felices nos dii faciant

(CIL, IV, 8670)

[Aqui habitamos. Que os deuses nos façam felizes]

5. Hic habitat felicitas [Aqui mora a felicidade] ${ }^{13}$

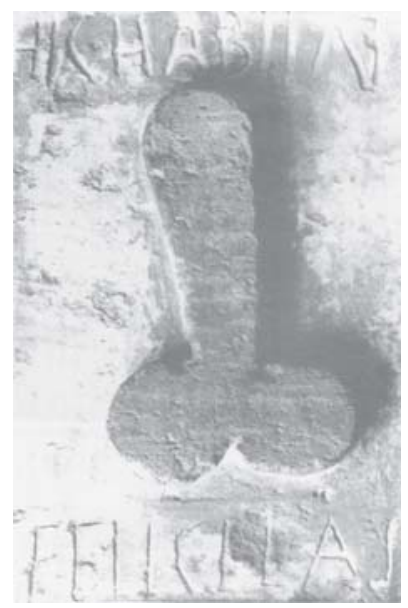

Figura 1 - Imagem do falo

Nos grafites 1, 3, 4 e no painel, representado pelo número 5, os termos traduzidos como "felicidade" são advérbios, adjetivos ou substantivos (feliciter, felices, felicitas) derivados de um mesmo termo latino "felix". Em seu sentido original, felix significa "fértil", "fecundo", "favorável", tornando seus derivados termos que significam a um só tempo "felicidade", "fertilidade", "abundância" e "sorte". Por outro lado, no grafite 2, o termo encontrado para designar felicidade é gaudia que pode ser traduzido como "alegria", "gosto do bem presente", "prazer interior". Estes diferentes sentidos são fundamentais para interpretarmos as inscrições selecionadas.

13 Imagem retirada de: FUNARI, P. P. A. Falos e representações sexuais: representações romanas para além da "natureza". In: FUNARI, P. P. A. et al. (Orgs.). Amor, desejo e poder na Antigüidade: relações de gênero e representações do feminino. Campinas: Editora da Unicamp, 2003. 
A primeira é uma súplica amorosa feita a Grata, intermediada pela deusa Vênus, para que esta receba felicidade eterna e não se esqueça do amor que vivera com o autor da inscrição. Já os grafites 3 e 4 são registros de momentos vividos e desejos de que os enamorados sigam juntos com a permissão dos deuses. Todos estes grafites se referem ao campo afetivo e, como destaca Feitosa, não necessariamente se remetem a uma idéia muito difundida na historiografia na qual os homens, por serem virtuosos, teriam que manter suas companheiras sob suas ordens como símbolo de sua masculinidade.

O que percebemos nestas inscrições não são relações de poder hierárquicas que foram fixadas na historiografia clássica como a única forma de relação afetiva entre homens e mulheres no mundo romano. Este tipo de interpretação, na qual o homem é viril e detentor do poder de comandar a vida política, as relações afetivas e, conseqüentemente, serem ativos nas relações sexuais, são cunhadas a partir de interpretações de leis e textos escritos pela elite romana. Se observarmos com atenção, é possível perceber, segundo Feitosa, que súplicas masculinas por felicidade e amor, como o grafite direcionado à Grata; compartilhamento de bons momentos entre casais apaixonados ou do pedido de proteção aos deuses para que a felicidade siga em suas casas, aparecem com mais freqüência do que se pensava, proporcionando uma maneira menos hierárquica de perceber as relações afetivas, ao menos entre as camadas populares da cidade de Pompéia.

A inscrição 3 também se insere em um ambiente emotivo, com destaque para a dor e a frustração amorosa. Percebe-se claramente, no início da inscrição, que o termo gaudia foi empregado para opor o prazer do presente a uma possibilidade de retorno no amanhã, o que indica a relação da felicidade com o presente vivido e não com uma tênue esperança de reencontro futuro. Além disso, é possível entender que esta felicidade expressa pelo autor do grafite deve ser compartilhada, a exemplo das inscrições anteriores.

Com relação à inscrição de número 5 , acredito que esta não pode ser analisada separada da escultura do falo em baixo-relevo. Originalmente encontrada fora de um edifício pompeiano, o conjunto escrita/relevo indica que o termo "felicitas" deve ser entendido no contexto apotropaico, isto é, de busca de proteção. As representações fálicas são muito presentes em Pompéia e o caráter mágico destas imagens tem sido mais considerado en- 
tre os especialistas. Funari, em uma análise do baixo-relevo, afirma que o falo desta inscrição não só afastava o mal olhado, função de um objeto apotropaico como a figa, como também trazia sorte e felicidade, atrelando a imagem fálica de fertilidade com a possibilidade de boa fortuna. ${ }^{14}$ Há muitas imagens e objetos que atrelam o membro masculino em ereção com a percepção de vida, fecundidade e sorte. Neste sentido, ao depararmos com uma inscrição como esta é preciso repensar nossos valores, evitando restringir a idéia de sexualidade à pornografia, tão comum em nosso meio, mas buscar compreender a sexualidade antiga dentro das particularidades dos costumes romanos que se constituem de maneira distinta à moral moderna. ${ }^{15}$

Para entender melhor esta relação, Cavicchioli ${ }^{16}$ afirma que no mundo romano a sexualidade não era uma esfera compartimentada da vida, mas era influenciada por outros aspectos como a moral e a religiosidade. Neste sentido, mais do que isolar os elementos ligados à sexualidade, no interior da cultura romana é preciso perceber que a sexualidade fazia parte da religião e vice-versa, constituindo uma mesma realidade. Neste momento em que uma inscrição como esta foi feita em Pompéia, a moral cristã ainda não estava presente e, conseqüentemente, não há vinculação do sexo a noção de pecado. As divindades romanas eram sexualizadas, expressavam desejos e o ato sexual se vinculava à idéia de fertilidade dado o potencial de procriação do ato sexual. Neste sentido, a inscrição de número 5, pensada em um contexto no qual as representações fálicas são abundantes, indica que separar a esfera sexual do religioso no mundo romano é mais um preconceito moderno do que uma percepção antiga. Funari, no referido estudo, aponta para a necessidade de nos despirmos de nossos próprios juízos de valores para perceber que a relação entre "felicidade" e "sorte", entendida no contexto apotropaico, pode apresentar um outro olhar sobre a cultura romana. Perceber que o falo, elemento da fertilidade, pode trazer boa fortuna e felicidade é uma maneira de entender a recorrência deste símbolo seja

14 FUNARI, P.P.A. Falos e representações sexuais: representações romanas para além da “natureza". In: FUNARI, P. P. A. et al. (Orgs.). Amor, desejo e poder na Antigüidade: relações de gênero e representações do feminino. Campinas: Editora da Unicamp, 2003.

15 Sobre esta questão, cf.: OLIVA NETO, J. A. Falo no jardim: Priapéia grega, Priapéia latina. Campinas: Editora da Unicamp, 2006.

16 CAVICCHIOLI, M. R. As representações da sexualidade na iconografia pompeiana. Dissertação (Mestrado) - Departamento de História, Unicamp, Campinas, 2004. 
em objetos decorativos, como anéis ou broches, como nas paredes de casas de Pompéia.

A partir destas breves considerações é possível afirmar que as cinco inscrições aqui reunidas apresentam percepções diversas de "felicidade", pois reúnem sentimentos que são distintos em nossa sociedade como proteção, abundância e sorte. Registros de afetividade mesclada com pedidos de proteção aos deuses; desejo de se consolidar no presente a alegria de viver e compartilhar sentimentos; a importância do "aqui", tantas vezes escritos nos muros (hic); de gozar os prazeres da vida agora e não em outro tempo; de realizar sonhos com pessoas queridas; de afastar o mau agouro e buscar proteção contra as mazelas da vida, eis alguns dos significados de felicidade expressos nas paredes de Pompéia. Significados estes que indicam a relação dos populares com seus deuses, com seus entes queridos, enfim, com o gozo pela vida em uma relação que extrapola o campo do sensível indicando percepções do mundo, maneiras de agir e pensar sua realidade.

Neste contexto, é possível entender os escritos nas paredes pompeianas em uma dimensão pública na qual se exterioriza para o coletivo sentimentos individuais. Durante muito tempo, os estudiosos do mundo clássico desqualificaram as ações das camadas populares, muitas vezes referindo-se a elas como populacho, como uma turba desorientada a ser trata a pão e circo. ${ }^{17}$ No entanto, ao lermos as paredes de Pompéia é possível depararmos com reflexões sobre o cotidiano, sobre sentimentos que os reúnem e que, quando compartilhados, trazerem a felicidade de viver cada momento. Noções estas que nem sempre estão de acordo com os textos produzidos pela elite romana, mas expressam a diversidade desta cultura e multiplicam os sentidos das experiências de vida. Como já alertava Funari, os grafites de Pompéia rompem o cotidiano, questionam, fazem pensar. ${ }^{18}$ Tais registros possibilitam uma percepção mais heterogênea da vida entre os romanos, abrem espaço para pensarmos novas formas de subjetivações e trazem o espaço público, mais uma vez, para o centro das atenções. Os grafites, em sua fragmentação, eternizaram sentimentos fugazes e, com isso, permitem um olhar plural para os romanos e suas formas de sociabilidades.

17 Para uma crítica a esta abordagem, cf.: GARRAFFONI, R. S. Gladiadores na Roma Antiga: dos combates às paixões cotidianas. São Paulo: Annablume/ FAPESP, 2005.

18 FUNARI, P. P. A. Cultura(s) dominante(s) e cultura(s) subalterna(s) em Pompéia: da vertical da cidade ao horizonte do possível. Revista Brasileira de História, v. 13, n. 7, p. 33-48. , 1986. 


\section{Considerações Finais}

Iniciei esta reflexão me referindo a dinâmica do pensamento de Hannah Arendt, sua crença nas ações humanas e na maneira particular com que estabelece a relação presente/passado. Gostaria, portanto, de encerrálo recorrendo mais uma vez as suas percepções. Para tanto, destaco que não pretendo com isto tornar as palavras de Arendt um modelo ou método para entender as particularidades do mundo romano, mas pelo contrário, chamar a atenção de como seu pensamento pode ser uma fonte de inspiração para leituras menos normativas do passado clássico. Ao valorizar o mundo clássico, em especial o romano, e contrapô-lo ao seu presente, Hannah encontrou meios para desconstruir verdades e repensar as formas pelas quais excluímos a singularidade e a pluralidade.

Esta particularidade de seu pensamento fez com que criasse uma crítica avassaladora do totalitarismo e, ao mesmo tempo, abriu a possibilidade de refletirmos sobre a ação no mundo, nossa relação com o outro e os sentimentos envolvidos em nossas teias de sociabilidade como amor e felicidade. A necessidade de problematizar idéias, pensamentos e crenças proporcionou uma faceta do agir politicamente: a alegria de compartilhar. Ao trazer os sentimentos para o campo político, Arendt inspirou historiadores a pensar as formas de sensibilidades em suas particularidades históricas.

A partir destas noções é possível olhar o mundo romano por um prisma pouco explorado pelos historiadores: o dos sentimentos. Pensar a felicidade no mundo romano é, em minha opinião, um desafio instigante. Considerando a vastidão que o império romano atingiu em seu auge, acredito que seja impossível definir uma única maneira de perceber e vivenciar a felicidade. É por isso que a Arqueologia, por meio da análise das inscrições, torna-se uma ferramenta importante para pluralizarmos as percepções romanas. Ao trazermos a cena os escritos populares, é possível pensar a felicidade em suas múltiplas acepções ou seja, não restringimos seu entendimento pelo viés de uma camada da população, a aristocrática, mas diversificamos sua potencialidade considerando as especificidades locais. Pensar esta diversidade é, portanto, um caminho profícuo para percebemos outras formas de celebrar a vida e agir no mundo. 


\section{Agradecimentos}

Gostaria de agradecer à Marionilde Brepohl de Magalhães pelo convite em participar deste evento comemorativo dos cem anos de nascimento de Hannah Arendt e o apoio do Instituto Goethe, além do apoio instituicional da UFPR e do NEE/Unicamp. Cabe mencionar, também, meus agradecimentos aos seguintes colegas por estes anos de diálogo: Marina Régis Cavicchioli, Lourdes Feitosa, Pedro Paulo Funari e Glaydson José da Silva. A responsabilidade das idéias recai apenas sobre a autora. 